\title{
¿QUÉ ESTÁ EN JUEGO AL OPTAR ENTRE DISTINTAS FORMAS DE APOYO PARA EL SECTOR CULTURAL?
}

\author{
Bruce Seaman \\ Georgia State University
}

\begin{abstract}
Resumen: En esta conferencia, Bruce Seaman realiza una tipología de algunos de los instrumentos de políticas públicas que existen en el ámbito cultural. Para ello, a partir de múltiples experiencias internacionales y de la evidencia existente, describe lecciones específicas que se pueden obtener para la industria cinematográfica, los museos y el patrimonio urbano.
\end{abstract}

PAlabras Clave: cultura, política cultural, instrumentos, subsidios, incentivos.

\section{WHAT IS AT STAKE IN THE CHOICE BETWEEN DIFFERENT FORMS OF SUPPORT FOR THE CULTURE SECTOR?}

ABSTRACT: In this lecture, Bruce Seaman presents a typology of some public policy instruments in the cultural sphere, drawing on numerous international examples and the available evidence to describe specific lessons for the cinema industry, museums and urban heritage.

KEYWORDs: culture, cultural policy, instruments, subsidies, incentives.

Bruce Seaman. PhD por la Universidad de Chicago. Profesor asociado del Andrew Young School of Policy Studies, de la Georgia State University. Email: bseaman@ gsu.edu.

* Versión revisada de la conferencia expuesta durante el simposio "Instrumentos de apoyo a la cultura: ¿qué está en juego?”, organizado en el CEP el 24 de noviembre de 2016. 


\section{INTRODUCCIÓN}

$\mathbf{L}$

a pregunta más recurrente en materia de política cultural siempre ha sido: ¿Existen razones para subsidiar las artes a través de impuestos públicos? No es el punto de discusión de esta conferencia. Asumimos que las políticas públicas tendientes a fortalecer las actividades artísticas y el sector cultural son, por lo general, legítimas y defendibles. Nuestra preocupación se centra más bien en las siguientes preguntas: ¿Cuáles son las opciones en materia de política? ¿Existe alguna evidencia respecto de su efectividad? ¿Qué enseñanzas pueden aplicarse al caso chileno a partir de la experiencia de otros países en cuanto al diseño y la implementación de diferentes opciones de política? ¿Existen lecciones específicas para sectores culturales relevantes, como la industria cinematográfica, los museos y el patrimonio cultural - especialmente respecto de la preservación de barrios históricos-, que puedan aplicarse al contexto chileno?

Como la interrogante inicial suele centrarse en la pertinencia de un subsidio a la cultura y las artes, los libros técnicos y las revistas académicas por lo general han prestado considerable atención a los subsidios públicos directos, ya sea unitarios o globales, a los proveedores y productores, y a la forma en que los organismos nacionales o regionales relacionados con las artes o entidades ministeriales administran dichos programas. Pero las herramientas de apoyo estatal a este importante sector de la economía y de la vida social son mucho más complejas y variadas. Nuestro argumento central es que las personas abocadas al sector creativo de la economía debieran tender a aplicar esa creatividad a la comprensión de estas opciones de política para constituirse en defensores más efectivos de la estabilización y expansión de este sector de la economía.

$\mathrm{Si}$ en lugar de repetir viejos mantras sobre la importancia de entregar subsidios a las organizaciones relacionadas con la cultura y las artes o directamente a los artistas, los esfuerzos se centraran en el diseño de una estrategia más amplia y variada de defensa de la cultura y las artes, se podría aglutinar a una gama más rica de aliados para desarrollar las opciones de política necesarias para asegurar la salud del sector cultural. Esto no significa ignorar que los subsidios directos a los agentes artísticos y culturales, así como la búsqueda de "fuentes de financiamiento dedicadas" (por lo general, impuestos destinados a la 
cultura y sectores afines) siguen siendo parte de una estrategia racional de promoción. Se trata de comprender más cabalmente las fortalezas y debilidades de una mayor gama de opciones de política y entender por qué algunas son más efectivas que otras.

\section{CINCO GRANDES TEMAS}

Si se analizan detenidamente las estrategias internacionales en apoyo del sector cultural pueden extraerse muchas lecciones que varían en su naturaleza e importancia según los observadores. Pero existen cinco temas centrales que merecen especial atención. Los introduciremos inicialmente antes de proceder a un análisis más amplio, con un foco especial en la industria cinematográfica, los museos junto con el patrimonio y la preservación de barrios históricos. El primero de estos cinco puntos requiere una presentación más extensa.

\subsection{La variedad de opciones de política disponibles}

El punto más básico consiste en reconocer la existencia de por lo menos seis categorías de políticas públicas que han tenido una gran incidencia en el sector cultural.

La política de subsidios (1) ciertamente siempre será relevante, pero conviene destacar una opción potencial promovida por algunos economistas que ha ido suscitando creciente interés y ha sido objeto de implementación a gran escala, aunque con resultados dispares: subsidios a los consumidores y no a los productores, como los cupones para las artes y los espectáculos.

(2) Adicionalmente a la política de subsidios, existen importantes decisiones que deben tomarse en materia de política tributaria, específicamente políticas impositivas que afecten directamente a las instituciones artísticas y culturales, como la exención de impuestos sobre la renta para organizaciones sin fines de lucro, determinadas normativas relativas al tratamiento tributario de las donaciones o los préstamos de obras de arte y artefactos de colecciones privadas a museos, o la rebaja de impuestos a dueños particulares de propiedades patrimoniales restauradas y preservadas. Pero el mayor ingreso y la estructura impositiva sobre las ganancias de capital también pueden ser importantes factores 
para potenciar o reducir los incentivos a las empresas, fundaciones e individuos para que donen dinero a los beneficiarios del sector artístico.

Se suele mirar en menos el rol que juega un tercer tipo de política (3): el desarrollo y el esclarecimiento de un marco legal relacionado con las normas regulatorias, los derechos de propiedad, las obligaciones contractuales y las interacciones competitivas. Considerando la existencia de una gran cantidad de pequeñas organizaciones culturales y artísticas sin fines de lucro y, por lo general, muy vulnerables en términos financieros, o, en el otro extremo, la presencia de grandes museos, orquestas y óperas locales de carácter monopólico y con financiamiento estatal, estas políticas pueden parecer relativamente inaplicables. Sin embargo, las regulaciones relativas a la posesión y la transferencia de antigüedades y el grado de control que pueden llegar a tener los estudios cinematográficos de Hollywood, de tradicional integración vertical, sobre la exhibición, la producción y la distribución de películas sin violar leyes antimonopolio, sugieren otra cosa. Y existe un debate permanente sobre la conveniencia de que las políticas públicas promuevan con fuerza una mayor consolidación en el sector no lucrativo que incluye a las organizaciones artísticas y culturales, lo que implicaría menos competencia y más cooperación, y que se expresa en la interrogante: ¿No existe acaso una excesiva fragmentación de las organizaciones sin fines de lucro? Incluso en algunas grandes capitales culturales, como Berlín o Nueva York, el tema de la cantidad sustentable de compañías de ópera o danza ha planteado interesantes interrogantes acerca de una "competencia desastrosa".

Una cuarta (4) categoría de política pública se relaciona con las reglas que debieran formar parte de los acuerdos comerciales internacionales. Antes de la actual arremetida populista contra el internacionalismo, el sector cultural es uno de los que han concitado mayor atención respecto a los potenciales efectos negativos de un mayor intercambio de bienes y servicios. Países como Canadá y Francia han abogado de manera insistente por exenciones proteccionistas para defender su patrimonio cultural ante el "imperialismo cultural" personificado en la importación de películas y música de países como los Estados Unidos.

Las políticas relacionadas con el empleo, el mercado laboral y el capital humano representan una quinta (5) área de políticas públicas que van más allá de un mero foco en los subsidios. Algunos de los ejemplos más claros de "la ley de las consecuencias imprevistas" se han obser- 
vado en iniciativas — bien intencionadas - para aumentar el empleo de artistas, mejorar las tarifas que reciben por su labor artística y volver más asequible su formación. Estas iniciativas - tendientes a crear una demanda "artificial" para los productos artísticos (como financiar a través de impuestos la compra y el almacenamiento de obras pictóricas no vendidas), modificar los derechos de propiedad para fortalecer el precio de reventa de las pinturas que es captado por el artista original (como con las leyes droit de suite) o posibilitar que personas con talento artístico puedan consagrar una mayor parte de su tiempo a labores creativas en lugar de dedicarse a otros aspectos de sus múltiples actividadeshan sido muchas veces identificadas como "las razones por las cuales los artistas son pobres" (Abbing 2002).

Y por último, un sexto (6) tipo de política, aparentemente relacionado pero singular, apunta a la política educativa, especialmente cuando ella no se relaciona con la capacitación de los proveedores de bienes culturales, sino con los potenciales demandantes (o consumidores) de esos productos. Pueden haber importantes interdependencias entre este tipo de política y, por ejemplo, la entrega de subsidios a los consumidores, como los "cupones de espectáculos", en la medida en que las opciones escogidas por sus destinatarios tenderán a reflejar la cantidad de "capital humano de consumo de arte" que posean, lo que les permitiría entender y disfrutar de eventos y espectáculos culturales en lugar de orientar ese gasto adicional a otras formas más "populares" de entretenimiento, que requieren menos bagaje cultural. Sigue siendo un importante tema de investigación dilucidar si el enfoque más efectivo para desarrollar ese bagaje cultural es ampliando la educación general, el alfabetismo y el acceso a carreras en institutos y universidades, o se deben focalizar los esfuerzos en la educación artística, especialmente a temprana edad (tomando en consideración los frecuentes recortes presupuestarios que se realizan en las escuelas primarias y secundarias a los programas de música y de artes).

\subsection{El supuesto de que las soluciones públicas y privadas constituyen alternativas, nunca complementos}

Por lo general, las políticas culturales operan a partir del supuesto de que las fallas de mercado del sector privado para generar la cantidad y calidad "óptimas" de bienes culturales han producido un vacío que 
debe ser colmado por el sector público. Esto transforma la intervención gubernamental en un sustituto para soluciones del sector privado, y atenúa el entusiasmo para buscar asociaciones público-privadas innovadoras que permitan "internalizar externalidades positivas netas" de la actividad cultural y llevar la producción a niveles más óptimos. Este foco excesivamente estrecho ha fomentado la falsa creencia de que la preservación del patrimonio es resorte exclusivo del sector público (Seaman 2013; Noonan 2013), o que las numerosas iniciativas para obtener mayor apoyo financiero del sector privado y empresarial para los museos afectará inevitablemente su "calidad e integridad". La realidad es mucho más compleja y no se limita a la complementariedad creada por agencias gubernamentales nacionales, que entregan fondos pareados - matching grants - a organizaciones culturales que pueden usar este capital inicial para estimular la filantropía privada o el apoyo gubernamental a nivel regional y local.

Entre los ejemplos más interesantes cabe citar la creciente popularidad de las Zonas de Regeneración de Barrios (Neighborhood Improvement Districts, NID), por lo general autorizadas por una legislación gubernamental específica, que "contemplan la existencia de un organismo autónomo y privado con la potestad de fijar impuestos adicionales sobre la propiedad en la zona con el objetivo de fomentar las metas del plan del NID, que por lo general consiste en la ampliación de servicios públicos o mejoras estructurales o ambos" (Georgiou 2011). Inicialmente una iniciativa innovadora canadiense de fines de los años sesenta, los NID ahora son populares en Australia, Nueva Zelanda, Japón, Sudáfrica, Serbia, el Reino Unido y los Estados Unidos, y siguen propagándose (Georgiou 2011; Ward 2007). Constituyen la quintaesencia de una asociación público-privada en la que los dueños de una propiedad (a veces sólo dueños de una empresa) dentro de una determinada área geográfica "se ofrecen" para que se les apliquen impuestos adicionales, por lo general basados en tasas y cobrados como impuestos sobre la propiedad. Las ganancias obtenidas son asignadas al municipio local para que las entregue a la gestora del programa NID, que se encargará de contratar la ejecución de vías peatonales más amplias y amigables, nuevas ciclovías, mejores parques locales, mayor protección policial, mejoras estructurales o cualquier proyecto que pudiera mejorar la calidad de vida de ese barrio. 
Otra modalidad de asociación pública-privada muy recurrente en los Estados Unidos para promover el desarrollo comunal y financiar grandes proyectos de mejora de la infraestructura cultural son las Zonas de Asignación de Impuestos (Tax Allocation District, TAD) o financiamiento a través del incremento tributario. En este esquema, los gobiernos locales y muchas veces los distritos escolares se endeudan mediante bonos, generalmente a 25 años, para realizar obras de infraestructura, cuyos intereses luego se pagan con el incremento del impuesto territorial que se obtiene gracias a la mejora general de dicha zona. Así, el gobierno local invierte en espacios verdes, museos, paseos y ciclovías y otros proyectos diseñados para incrementar de manera significativa el valor de las propiedades en el largo plazo, lo que permite retirar los bonos y generar una fuente más estable y de largo plazo de ingreso por contribuciones para estas entidades públicas. Estos son algunos ejemplos creativos de iniciativas público-privadas para resolver grandes problemas de "externalidades" y mejorar la infraestructura cultural, definida en términos generales.

\subsection{Valorizar monetariamente las estrategias es importante}

El tercer tema es también fácilmente olvidado en un sector por lo general no centrado en la propiedad privada ni en la maximización de utilidades: la importancia de las estrategias de fijación de precios. A veces los precios son importantes simplemente para que los proveedores de servicios puedan desarrollar una combinación óptima de fuentes de ingreso. En otros casos son claves, pues entregan señales tanto a los clientes como a los proveedores de servicios que deben lidiar con los inevitables temas de racionamiento causados por la escasez. Esto es cierto tanto para la gestión de museos estatales como para la mantención y preservación del patrimonio cultural, el desarrollo de esquemas de incentivo para coordinar la compleja tarea de reunir una amplia variedad de contratistas independientes en la producción y distribución de películas, y el desarrollo de estrategias por parte de los administradores de las orquestas sinfónicas, compañías teatrales, que abarcan desde grandes compañías de Broadway hasta pequeños grupos teatrales de barrio o compañías de ópera y danza. La fijación de precios es a veces responsabilidad directa de los diseñadores de políticas públicas, como 
en el debate sobre dónde y cuándo — si procede — cobrar entradas a los museos nacionales del Estado, o la decisión de cooperar en atractivos culturales del sector privado mediante la distribución de "multipases artísticos" $\mathrm{u}$ otros tipos de pases con descuento para turistas que visitan una ciudad o región. Incluso el tema de imponer "sobrecargos por congestión" en determinados sectores de la ciudad se puede ver más como un tema general relacionado con el racionamiento del espacio, al margen de si es aplicado en el distrito financiero de la ciudad de Londres o para el ingreso a ese "museo público" que constituye la ciudad de Venecia en su conjunto (Mossetto 1992). En otros casos, la influencia de la política gubernamental en materia de precios puede ser indirecta, como en la decisión de subsidiar una u otra organización de acuerdo con el grado de diligencia que ha mostrado la organización en generar más ingresos o el grado de éxito que ha mostrado en asegurar el acceso a un público diversificado (en ambos casos se requerirá una discriminación sofisticada de precios y contratos vinculantes; véase Seaman, 2010). Sea como sea, el tema de la fijación de precios es importante.

\subsection{El diseño de políticas culturales está especialmente expuesto a ser considerado elitista}

La cuarta lección central es muy relevante debido al creciente escepticismo mundial, cuando no la hostilidad abierta, hacia las llamadas élites y los considerados expertos. A pesar de que la "insurrección" populista ha tendido a ser más notoria por sus excesos que por su sentido común, resulta cada vez más patente que la promoción y la administración efectivas del sector cultural por parte de los ministerios y los organismos responsables de la política cultural están sujetas a un manejo cuidadoso respecto de la percepción de elitismo y falta de receptividad hacia públicos más amplios o en la toma de decisión relativa al reparto de los subsidios. Por lo general, esta recriminación está dirigida a los diseñadores de políticas a nivel nacional, que suelen verse implicados en luchas de poder y derrotas autoinfligidas con agencias locales y administradores regionales de las políticas que, con justa razón, reflejan con mayor certeza las opiniones y los valores del público que representan. Resulta difícil evitar una actitud de sospecha hacia los expertos en políticas nacionales y los "zares de las políticas", incluso cuando 
recurren a estrategias políticamente sensatas. Por ejemplo, es conocida la estrategia del National Endowment for the Arts (NEA) de los Estados Unidos de asegurar que los subsidios de capital inicial se repartan a través de todos los distritos congresistas del país para garantizar una amplia participación local en la supervivencia del NEA. Sin embargo, el NEA siempre ha tenido que lidiar con presupuestos muy limitados. El monto máximo que ha recibido fue de 176 millones de dólares en 1992, antes de tener que luchar por sobrevivir a los esfuerzos de los conservadores por suprimirlo del todo en los años noventa. A esto le siguieron presupuestos inferiores a los 100 millones hasta 2001, año en que volvieron a incrementarse hasta alcanzar otro máximo (167,5 millones) en 2010, para volver a caer a su actual nivel de aproximadamente 150 millones. En la actual propuesta presupuestaria del gobierno de Trump se plantea otra vez su total eliminación, a pesar de que la mayoría de los observadores apuntan a que esto no sucederá. La lección que puede extraerse es que una promoción efectiva en este sector debe ser lo más inclusiva posible, en consistencia con el mandato de mejorar y potenciar la identidad cultural y calidad del "patrimonio" nacional. Esto representa ciertamente un desafío, pero, como mínimo, invita a la formulación de una definición más amplia e ilustrada de lo que conforma la "cultura" y "las artes".

\subsection{Suele existir una brecha significativa entre el diseño de las políticas y su efectividad}

La quinta lección fundamental de una evaluación internacional de las políticas culturales fue esbozada al inicio de este artículo, en la discusión sobre algunas políticas orientadas a mejorar la condición económica de los artistas, políticas que han sido criticadas en varias ocasiones por generar un exceso de artistas, lo que suele traducirse en que los menos famosos reciban bajas remuneraciones. Éste es un ejemplo de la conocida pero siempre subvalorada "ley de las consecuencias imprevistas", cuya omisión representa para muchos economistas el foco principal de su trabajo. También existe un corolario: a veces, las "megapolíticas" aparentemente bien implementadas para cumplir con sus objetivos tienen resultados muy decepcionantes. Entre los ejemplos abordados más adelante en este trabajo figuran los resultados dispares de diversas 
iniciativas contra la "piratería", concebidas para proteger los derechos de autor de los creadores, así como las políticas comerciales proteccionistas diseñadas para proteger y fortalecer el sector creativo local de la "invasión" de productos masivos, los que, con gran financiamiento, son exportados desde naciones más poderosas, con lenguas internacionales dominantes, hacia regiones vulnerables. A pesar de algunos éxitos en las políticas proteccionistas, los resultados son dispares y representan una advertencia contra el supuesto de que las iniciativas de política bien intencionadas y aparentemente bien focalizadas siempre tienen éxito.

\section{ELABORACIONES DE ESTOS TEMAS GENERALES Y OPCIONES DE POLIITICA PÚBLICA}

\subsection{Importantes distinciones y aclaraciones en relación a la política de subsidios y de impuestos}

A pesar de que los subsidios son sólo una de las seis categorías de opciones de política (ver sección 2.1), siguen siendo un componente clave del diseño de políticas culturales. Para entender adecuadamente su función, es preciso formular cuatro importantes distinciones respecto de cómo se financian los subsidios y a quiénes están dirigidos.

i) Los subsidios directos de los presupuestos gubernamentales - gastos - provienen de la tributación general de la población o del endeudamiento a través de la venta de bonos estatales. Esto también puede materializarse a través de fondos pareados, para permitirles a los tomadores de decisiones en el sector privado asumir algunas elecciones específicas en materia de asignación de recursos y, a la vez, generar suficiente financiamiento para proyectos completos.

ii) Otros subsidios son canalizados hacia los receptores en las artes pero financiados a través de impuestos y tarifas a sectores específicos de la economía, como la televisión (incluidos los programas por cable y satélite), los cines o los radiodifusores, a los cuales se les puede aplicar una tarifa para obtener una licencia. Ésta es una forma común de financiamiento de subsidios para las industrias cinematográficas dentro de Europa, especialmente en Francia.

iii) Algunos subsidios son otorgados directamente a las organizaciones culturales y relacionadas con las artes, mientras que otros son 
entregados directamente a artistas u otros proveedores de servicios culturales.

iv) La opción preferida de algunos economistas son los subsidios directos a grupos específicos de consumidores para aumentar su consumo de servicios culturales, como, por ejemplo, el Vale Cultura en Brasil. A pesar de que los cupones constituyen una forma usual de apoyo para la obtención de bienes esenciales como alimentos y vivienda, en el sector cultural han concitado más respaldo de parte de los investigadores que de los gobiernos. Pero esto ha ido cambiando y, además de Brasil, existen otros países con programas de cupones culturales, como Finlandia, Bélgica, Italia, Austria y el Reino Unido.

También hay al menos seis aspectos relativos a la política tributaria que ameritan una aclaración.

i) Algunas deducciones y exenciones de impuestos han sido enfocadas directamente hacia instituciones culturales y relacionadas con las artes. Un ejemplo destacado es la exención total en materia de impuestos a la industria cinematográfica nacional en Corea del Sur, creada después de la Guerra de Corea.

ii) Los créditos tributarios directos operan de manera diferente de las deducciones de impuestos y confieren otros beneficios. El crédito es una reducción en la carga tributaria en contraste a la deducción, que es una disminución de la base imponible sobre el que el impuesto en cuestión es recogido. En consecuencia, el crédito suele ser más directo y efectivo que la deducción. Por cierto, la exención completa directa de impuestos es la más efectiva de todas estas herramientas.

iii) A veces el tema de discusión no es la elección entre tasas impositivas o créditos, por un parte, y deducciones, por otra, sino la idoneidad de diferentes tipos de organización para poder optar a algún trato impositivo favorable. Por ende, los cambios en políticas relacionadas con la deducción impositiva de las contribuciones a las organizaciones sin fines de lucro, que incluyen a muchas organizaciones artísticas y culturales, son importantes instrumentos de política. Estos cambios también pueden incluir topes en los montos deducibles en la declaración de impuestos de un individuo y que los beneficios tributarios de los contribuyentes de mayores ingresos tengan un tope fijado como un porcentaje del ingreso imponible o como un monto absoluto. 
iv) Los cambios en las tasas impositivas marginales sobre la renta, no así las tasas promedio, son claves para determinar el "precio" neto para particulares, fundaciones y empresas que donan a las organizaciones sin fines de lucro. Por ejemplo, a pesar de que un incremento general en el impuesto sobre la renta dentro de un país reducirá los ingresos disponibles y tenderá a reducir estas contribuciones al sector cultural, estos mismos impuestos más elevados hacen disminuir el costo neto después de impuestos (precio) por contribuir a esas organizaciones sin fines de lucro. Estos conflictos entre "ingreso puro" y "efectos relativos de sustitución de precios" son objeto recurrente de análisis por parte de los economistas en diferentes contextos.

v) Especialmente relevantes pueden ser las políticas relacionadas con impuestos sobre la propiedad e impuestos aplicados a las donaciones de cuadros, artefactos y otros objetos de colección a museos y galerías. Como ejemplos cabe citar la forma en que esas piezas de arte son valorizadas, las distinciones entre obsequios absolutos y préstamos de obras artísticas, y políticas como el "impuesto mínimo alternativo" -alternative minimum tax - en los Estados Unidos para asegurar que los contribuyentes de ingresos muy elevados no tomen una ventaja indebida de deducciones de impuestos legalmente permitidas que reducen excesivamente su carga tributaria.

vi) Las políticas tributarias también pueden incluir políticas específicas para incrementar el acceso a capital privado, no sólo con tratamientos impositivos favorables (como el 20 por ciento de crédito tributario por gastos de producción cinematográfica hasta cierto máximo por película), pero puede también incluir un impuesto sobre el valor agregado (IVA) reducido para productos electrónicos y físicos, y diversos esquemas de garantía para préstamos.

\subsection{Elaboraciones sobre aspectos regulatorios, legales y competitivos de las políticas, incluidos temas relacionados con el comercio internacional}

El alcance de este tipo de políticas puede ser muy amplio y abarcar algunos temas controvertidos. Por ejemplo, incluye políticas relacionadas con el manejo de artefactos y otros objetos patrimoniales, las que pueden verse sumidas en controversias internacionales como la repa- 
triación de objetos que han permanecido durante un largo tiempo fuera de su país de origen. También pueden contener severas restricciones a los derechos legales de los ciudadanos y la imposición de obligaciones específicas relacionadas con el acceso a objetos culturales y la mantención de propiedad considerada como parte del patrimonio cultural.

Otro tema de especial relevancia en la era digital es determinar la forma óptima de imponer restricciones a la descarga y el intercambio de archivos de música, películas y otros contenidos culturales como parte de políticas relativas a la protección de la propiedad intelectual a través de leyes de derechos de autor. Esto se ha traducido en el decomiso de servidores por parte de las autoridades policiales o el cierre de determinados sitios web que infringen las leyes sobre derechos de autor.

Un problema de otra índole, que no está vinculado con los enormes cambios tecnológicos, es el establecimiento de estándares para la transmisión de objetos artísticos de valor, como el controvertido tema de "deshacerse" de objetos artísticos de valor donados por patrocinadores acaudalados con la expectativa de que permanezcan en manos de la institución receptora original. Muchas veces, se trata de un tema relacionado con la fijación de estándares éticos en el sector museográfico más que de un asunto relacionado con leyes y regulaciones estatales. Sin embargo, para los museos que operan con financiamiento público, la política gubernamental respecto del grado de autonomía que se les debe conferir a los administradores de los museos en cuanto a la composición de sus respectivas colecciones puede ser un tema clave de política. E incluso cuando los museos operan con fondos privados, pueden producirse demandas legales relacionadas con el intento de vender parte de la colección, lo que incorpora al sistema legal como un actor adicional.

A pesar de que no es un tema central en el ámbito cultural y de las artes, a comienzos de los años 2000 se produjeron acciones legales contra la fijación monopólica de precios por parte de las casas de remates de obras de arte Sotheby's y Christie's. Asimismo, en los Estados Unidos, la Federal Trade Commission (FTC) entabló una demanda por colusión contra Warner Brothers y Vivendi Universal por su marketing y política de precios en relación con algunas de las grabaciones de los superestrellas de fines de los años noventa y comienzo de los 2000, los Tres Tenores (Plácido Domingo, José Carreras y Luciano Pavarotti). Los mismos Tres Tenores se vieron involucrados en disputas legales 
con el gobierno alemán en relación con el pago de regalías (Breslin 2004).

Un ejemplo de política competitiva, a pesar de que no implica disputas legales, es la eventual preferencia por museos estatales "monopólicos" o museos estatales "competitivos" cuando la política de museos es muy centralizada, como lo fue históricamente en Italia. Algunas investigaciones han evidenciado que los gobiernos prefieren que las funciones complementarias (es decir, la conservación y la investigación científica) sean producidas por un mismo museo, mientras que las funciones sustituibles (por ejemplo, la conservación y el acceso por parte del público general) sean asumidas por dos o más museos (Fedeli y Santoni 2006). Italia ha realizado cambios radicales en su política cultural, con muchas más privatizaciones, pero existen muchos países con museos estatales para los cuales esto es potencialmente relevante.

Las leyes de droit de suite han sido implementadas en varios países (en el Reino Unido, en Francia, determinadas regiones de los Estados Unidos, Australia, Filipinas y dentro de la Unión Europea, entre otros), a fin de garantizar legalmente que los pintores se beneficien en parte de los precios más altos que logran las reventas de sus obras. Los economistas han dudado respecto del impacto real de esas leyes, pero un estudio reciente realizado en el Reino Unido no halló ningún efecto negativo de dicha ley sobre los precios originales (Banternghansa y Graddy 2011).

Finalmente, un tipo de política hacia la competencia se centra en el comercio internacional y el desplazamiento de bienes y servicios de un país a otro. Como se señaló en la sección 2, esto ha sido especialmente relevante en el caso de la industria cinematográfica, donde países como Canadá y Francia han sido estrictos a la hora de diseñar políticas para proteger sus industrias cinematográficas nacionales, incluso en la era de los tratados de libre comercio y de las reglas específicas del Acuerdo General sobre Aranceles Aduaneros y Comercio (General Agreement on Tariffs and Trade, GATT). Pero el proteccionismo en la industria cinematográfica incluye muchos otros ejemplos, como el establecimiento en Corea del Sur, en 1973, de un número de días en que podían exhibirse películas extranjeras en las salas del país. A pesar de que la mayoría de las estrategias proteccionistas restrictivas se han visto limitadas por los acuerdos de libre comercio, aún siguen de alguna manera vigentes 
en países como Francia. Internet plantea desafíos especiales para una implementación exitosa de esas estrategias, pero incluso así no han desaparecido. Las políticas para intercambiar colecciones de museos entre países - diseñadas para facilitar el intercambio-, así como las restricciones sobre el tráfico de artefactos "patrimoniales" culturales, también son relevantes.

\subsection{Políticas relacionadas con el empleo, el mercado laboral y el capital humano}

A pesar de que las políticas relacionadas con el empleo, el mercado laboral y el capital humano pueden incluir subvenciones directas a los artistas e inscribirse en el marco de una política de subsidio, existen algunos temas específicos que conciernen a los mercados laborales de los artistas y que han motivado iniciativas especiales de política. Por ejemplo, muchos artistas y trabajadores del sector cultural son independientes y tienen múltiples empleos (véase, por ejemplo, Throsby y Zednik 2011). Gran parte de las veces tienen que hacer malabarismos entre "trabajos creativos" (como componer música), "trabajos relacionados con las artes" (enseñarles música a los niños) y "trabajos no artísticos" (procurar un ingreso principal laborando para una empresa). Esto ha llevado a que con financiamiento estatal economistas en Eslovenia realicen estudios, por ejemplo, sobre los efectos de determinadas reformas sobre el trabajo artístico y sobre el ingreso general, tales como: (1) planes de salario mínimo; (2) alternativas a las cotizaciones de previsión social; (3) oferta de servicios de contabilidad gratuitos, y (4) diversas reformas al sistema de pensiones (Sraker et al. 2016). Los hallazgos preliminares sugieren que medidas como permitir que los artistas se muevan con mayor flexibilidad entre un esquema independiente y dependiente de empleo sin que esto afecte negativamente sus imposiciones o que puedan optar a programas fiscales de apoyo monetario cuando se encuentran cesantes o a estipendios de trabajo son especialmente promisorias para reducir la brecha de ingreso entre los artistas independientes y otras profesiones. Otros enfoques, como elevar los límites para poder optar a diferentes formas de apoyo, demostraron ser sobre todo útiles para los artistas independientes más pudientes y, por ende, ser menos efectivos. Otras reformas son más políticas en su 
esencia, como promover la formación de un sindicato para los artistas independientes.

Algunas formas de apoyo han sido mal diseñadas, como las garantías brindadas a los artistas en el pasado por el Estado holandés respecto a que cualquier pintura sería adquirida por el Estado si no pudiera ser vendida. Esto no sólo se tradujo en un superávit de pintores, con consecuencias negativas en el largo plazo, sino también en la necesidad de almacenar una gran cantidad de pinturas inservibles. Otro plan con consecuencias negativas imprevistas fue un "seguro de desempleo para los artistas escénicos" instaurado en Francia en los años noventa (Towse 2010 plantea una buena discusión sobre estos programas).

Un caso interesante, que no requiere una política gubernamental explícita, pero que podría ameritarla si los estándares establecidos de manera privada no brindaran una adecuada protección, es el desafío relativo a los derechos de los trabajadores y los estándares laborales como resultado del fuerte incremento de voluntarios que ayudan al personal profesional en los museos alrededor del mundo, en lo relacionado - aunque no de manera exclusiva - con temas de conservación del patrimonio. La Federación Mundial de Amigos de los Museos (World Federation of Friends of Museums, WFFM) estableció un código de conducta para guiar la relación entre los voluntarios y el personal pagado de los museos, enfoque que influenció en gran medida iniciativas similares desarrolladas posteriormente en el siglo XXI por el Consejo Internacional de Museos.

\subsection{Un breve análisis sobre política educativa}

Considerando que el objetivo de la mayoría de los países es lograr que los activos artísticos y culturales, entre ellos sus propios activos locales, estén accesibles a un porcentaje más amplio de la población y no sólo a las élites con mayor nivel educativo y económico, siempre se ha debatido en torno a la mejor forma de lograrlo. Algunos argumentan que si se pone el acento en los subsidios a la educación y en una educación artística focalizada se podrían reducir sustancialmente otras formas de subsidio a las artes. Las investigaciones económicas sugieren que no es así (Chamarnaud et al. 2008), a pesar de que la educación artística es objeto de un gran debate presupuestario en países alrededor del mundo en la medida en que deben hacer frente a serios desafíos fiscales. 
La política educativa está también relacionada con esfuerzos por estimular un mayor acercamiento a las artes y la cultura a través de cupones culturales, como el plan Vale Cultura de Brasil. Existe considerable evidencia en el sentido de que este último enfoque no ha sido especialmente efectivo para estimular la demanda hacia las "artes más elevadas", aun cuando aquél no era el único objetivo de éste u otros planes similares (Souza et al. 2016).

\section{APLICACIONES ESPECÍFICAS AL SECTOR CINEMATOGRÁFICO}

El sector de la producción y distribución cinematográfica plantea temas específicos de política, puesto que suele estar conformado por empresas privadas con fines de lucro para las cuales el apoyo público es más problemático de lo que suele serlo para los museos, que por lo general dependen de fundaciones sin fines de lucro o son operados por el Estado (a pesar de que en muchos países este sector depende crecientemente de ingresos directos más que de donaciones o de subvenciones estatales, a la vez que el apoyo y la gestión del sector privado son cada vez más usuales). Como se analiza a continuación, la preservación del patrimonio cultural es una combinación virtuosa de iniciativas públicas y privadas, y el rol del sector privado está creciendo en relación con el largo dominio que ha tenido el sector público en la preservación del patrimonio.

A pesar de que la industria cinematográfica chilena es mucho menos madura que la argentina, es cada vez más respetada a nivel internacional, lo que se refleja en el reciente Oscar al Mejor Cortometraje Animado y sus nominaciones en varios otros certámenes. También existen varios festivales de cine a lo largo del país, entre ellos los destacados festivales de Valdivia y Santiago. El empleo está creciendo, los fondos aumentan y los talentos y las películas chilenas son cada vez más llevados a las pantallas extranjeras, mucho más allá de las naciones del Mercosur.

Esto sugeriría que Chile tiene mucho que enseñarle a otras naciones acerca del desarrollo de un sector cinematográfico nacional, que debe enfrentarse a la todopoderosa y omnipresente industria de Hollywood. Pero vale la pena identificar algunos hallazgos importantes de investigación, que dicen relación con las opciones de política 
llevadas adelante en otros países y que pueden brindar valiosas enseñanzas a Chile. En continuación se plantean cinco lecciones para la discusión.

\subsection{La piratería es siempre una amenaza, pero las políticas para limitar sus efectos adversos pueden resultar inefectivas}

Un importante estudio reciente (Orme 2014) identifica grandes complicaciones en la efectividad, en el largo plazo, de las leyes contra la piratería y las acciones legales para proteger a la industria cinematográfica. El estudio utiliza métodos empíricos sofisticados para analizar los ingresos semanales por taquilla en los Estados Unidos en el período 1997-2014, tras seis intervenciones específicas de política tendientes a evitar que se infrinjan los derechos de propiedad intelectual a través de la piratería en línea. Tres puntos sucintos nos ayudarán a poner ese estudio en contexto.

i) Pese a la creciente (pero no consistente) evidencia de que la piratería de películas tiene un efecto negativo en los ingresos de los estudios cinematográficos, la evidencia respecto del impacto real de las leyes contra la piratería es limitada. Si cualquier legislación contra la piratería tuviera el efecto deseado, debería observarse un incremento sostenido en las ventas de la industria cinematográfica después de la aplicación de leyes que restringen el acceso a contenidos pirateados o del cierre de sitios web que ofrecen contenidos ilegales para su descarga.

ii) Sin embargo, de las seis políticas (descritas en términos básicos a continuación), una tuvo claros efectos positivos de corto y largo plazo en el incremento de los ingresos por taquilla, dos tuvieron efectos significativamente negativos sobre los ingresos de la industria cinematográfica (posiblemente al limitar el valioso intercambio espontáneo de información que siempre se ha identificado como un efecto potencialmente positivo de la piratería en las utilidades de la industria) y tres tuvieron efectos no significativos.

iii) Estos resultados son, por lo general, consistentes con la opinión comúnmente aceptada de que las leyes contra la piratería son, por lo general, difíciles de aplicar, lo que debilita su control sobre las descargas ilegales; y si bien pueden tener un efecto inmediato, resultan luego superadas por nuevas tecnologías e ingeniosas técnicas de evasión. 
Pero puesto que las seis políticas son bastantes agresivas en términos generales, conviene conocerlas más de cerca, lo que hacemos en los siguientes apartados:

a) La ley "No Electronic Theft" (NET), de 1997, fue la primera en facilitar la persecución a la violación de los derechos de propiedad intelectual en línea, de la misma manera como se protegía los derechos de propiedad intelectual tradicionales. Subir y descargar materiales protegidos se volvió una justificación suficiente para ser objeto de demandas judiciales. También llenó un vacío legal que apuntaba a la exigencia de que hubiera una ganancia monetaria directa para iniciar una demanda. Orme (2014) observó un efecto muy positivo en el largo plazo en los ingresos de la industria cinematográfica como resultado de la implementación de esta ley. Es la única de las seis en haber tenido este claro efecto. Puesto que fue la primera de las seis iniciativas legales, es probable que los buenos resultados logrados para la industria cinematográfica hicieran que las siguientes iniciativas fueran relativamente ineficaces para brindar protección adicional. También cabe pensar que las leyes posteriores fueron demasiado lejos y limitaron la capacidad de la piratería en línea para hacer correr la voz sobre películas de calidad (como ya se dijo, éste es un argumento recurrente de los defensores de la piratería). Puede también que las otras leyes hayan apuntado a un tipo de piratería que es difícil de identificar y de perseguir penalmente.

b) La ley "Digital Millenium Copyright" (DMCA), de 1998, fue parte de dos grandes tratados internacionales sobre protección de derechos de autor en los Estados Unidos, junto con otras medidas relacionadas. Se establecieron más sanciones por infracción de derechos de propiedad intelectual, penalizándose la elusión de controles contra la piratería (incluso si no se violan derechos de autor después de esa elusión) y se les confirió mayor grado de responsabilidad penal a las personas que colaboraran en la distribución de materiales protegidos. Esto parecía fortalecer la capacidad de aplicación de la ley. Sin embargo, el estudio observó efectos negativos en el largo plazo, a pesar de que tuvo efectos positivos en los ingresos por taquilla en el corto plazo.

c) A fines de los años noventa y comienzos de la década de 2000, Napster era la mayor fuente de descargas ilegales e intercambio 
de archivos. A pesar de que los archivos MP3 de música eran los más utilizados en esta plataforma, también se compartían películas. Pero el sitio fue cerrado en julio de 2001 por orden de una corte federal. Se esperaba que esto tuviera efectos, especialmente en la industria musical pero también en la industria cinematográfica. Sin embargo, el estudio no evidenció efectos beneficiosos estadísticamente significativos para los ingresos de esta última industria.

d) La ley "Family Entertainment and Copyright", de 2005, contenía dos disposiciones claves: penas más severas para las infracciones a los derechos de autor y la calificación de delito federal $-\mathrm{y}$ no sólo estatal - para los casos de grabación de material protegido en un espectáculo. Prohibió el ingreso de cámaras en los teatros y permitió que se sancionara a las personas aunque no hubiera evidencia de intento de distribuir dicho material. Algunos estados ya habían puesto en práctica esta normativa, pero esto aumentaba el alcance de la ley y endurecía las penas. Las grabaciones de video son una de las principales fuentes de contenidos pirateados en línea. El estudio nuevamente halló efectos positivos sobre los ingresos por taquilla, aunque sólo en el corto plazo. En el largo plazo, volvieron a ser negativos.

e) La ley PRO-IP, de 2008, contenía varias disposiciones e incluía tal vez el mayor incremento en las sanciones por infringir la propiedad intelectual. Permitía la incautación de activos materiales y financieros relacionados con la violación de los derechos de autor y creaba un cargo ejecutivo para la coordinación de la aplicación de la ley. Asimismo, asignaba fondos para proyectos contra la piratería y ampliaba los tipos de distribución de contenidos que podían clasificarse como violaciones a la propiedad intelectual. $\mathrm{Su}$ objetivo apuntaba a solucionar problemas a gran escala. Por ello, no resultó sorprendente que el estudio no encontrara efectos estadísticamente significativos sobre los ingresos de la industria cinematográfica.

f) Megaupload era un sitio web que permitía la reproducción de contenidos además de las descargas. Los fiscales federales estadounidenses interpusieron una demanda contra el sitio el 19 de enero de 2012 y el FBI procedió al decomiso de los servidores. Esta operación debería haber generado beneficios significativos para la 
industria cinematográfica, pero el estudio no pudo detectar significancia estadística alguna de esos efectos sobre los ingresos por taquilla.

Como sucede con todos los estudios empíricos, la calidad de los datos, la estrategia investigativa y el desafío de aislar los efectos de determinados factores entre muchos otros que podrían ser relevantes invitan a la prudencia a la hora de interpretar los resultados de Orme (2014), al menos hasta que futuras investigaciones entreguen evidencia que los confirmen o sugieran hallazgos contradictorios. Dicho eso, este estudio sugiere cautela en cuanto a la capacidad de las políticas públicas para enfrentar de manera adecuada las consecuencias del cambio tecnológico y los efectos potencialmente adversos de la piratería, el intercambio de archivos y la circulación de versiones no autorizadas en el sector cultural.

\subsection{La lección del proteccionismo cinematográfico}

Puede que el proteccionismo de una industria cinematográfica nacional ayude a reflotar un sector cinematográfico moribundo (como fue el caso en Corea del Sur), pero no es una estrategia especialmente efectiva en el largo plazo y, por lo tanto, no debe ser concebida como un sustituto de estrategias más robustas, como diversificar las fuentes de financiamiento, lograr acceso a más fuentes de capital financiero privado, diversificar los riesgos e invertir en la creación de talentos locales. Los economistas siempre han sido escépticos respecto de las estrategias proteccionistas, especialmente en la medida en que se relacionan con reglas aplicables a los contenidos locales y la viabilidad en el largo plazo de poner límites a la importación de películas extranjeras, especialmente en un mundo digital. Sea como sea, ¿qué es exactamente una película chilena? Si es financiada principalmente por inversionistas extranjeros, dirigida por un español que es también el protagonista de la película, pero trata sobre la notable epopeya de los mineros en Atacama, ¿es realmente una película chilena o una película extranjera sobre un connotado rescate ocurrido en Chile? Tal fue siempre el caso con las leyes canadienses sobre contenidos. Si una película a todas luces estadounidense es filmada en Toronto y no en Nueva York para abaratar costos, ¿hay algún motivo para considerarla una película canadiense? 
Cualquiera sea el caso, los datos sobre admisión en cines franceses entre 1949 y 2012 (el primer acuerdo que puso limitaciones a la exportación de películas estadounidenses a Francia fue en 1948) brindan un cuadro bastante dispar del éxito de ese tipo de proteccionismo. Como lo señala Hilary Barnes (2013), el porcentaje de admisiones de películas producidas en Francia ha sido básicamente constante durante ese período. En 1949, alcanzó el 42 por ciento y en 2012, el 40,3 por ciento, con un mínimo de 28,5 por ciento y un máximo de 51,2 por ciento en el año 1960. Las películas estadounidenses se han mantenido también bastante constantes, con un promedio de 43 por ciento y un mínimo de 28,5 por ciento en 1960 (año álgido de las películas francesas) y un máximo de 55,9 por ciento en 1990, seguido de un declive en las décadas siguientes hasta alcanzar el 42,7 por ciento en 2012. Puesto que el porcentaje de las otras películas europeas en las pantallas francesas sólo alcanzaba el 20,3 por ciento en 1960 , el 25 por ciento en 1970 y ha bajado a 15 por ciento o menos desde 1980, una interpretación "pro proteccionista" sugerida por Barnes es que la ausencia de un proteccionismo efectivo por parte de los otros gobiernos europeos afectó negativamente a sus propias industrias cinematográficas nacionales, mermando su capacidad para exportar películas hacia Francia.

Barnes señala que los partidarios franceses del proteccionismo siempre citan el declive de las industrias cinematográficas en el Reino Unido e Italia como evidencia de la necesidad de proteger. Sin embargo, las películas más exitosas exhibidas en Francia siguen siendo en gran medida de origen extranjero. Según datos de 2010 citados por Barnes, se exhibieron 61 películas que fueron vistas por más de un millón de personas, de las cuales sólo 7 fueron vistas por más de cuatro millones de personas, entre las cuales apenas una era francesa (14,3 por ciento). Hubo 19 películas con un público total que osciló entre dos y cuatro millones, de las cuales 7 eran francesas (36,8 por ciento) y 25 películas vistas por entre uno y dos millones de personas, de las cuales 11 de ellas francesas (44 por ciento). A pesar de que esta caída sostenida en el porcentaje de películas francesas en un escenario en que el público total crece puede interpretarse como un fracaso del proteccionismo frente a lo que se esperaba de éste, es probable que si en Chile los datos fueran similares se considerarían como una evidencia de éxito en el intento de acabar con la influencia dominante de películas extranjeras en las salas 
de cine nacionales. Otro tipo de evidencia económica ha demostrado que cuando la exhibición de películas está dominada por cadenas de cines, como es el caso en Chile, hay menos diversidad en términos de contenidos y origen de las películas. Por ende, una evidencia similar a la hallada en Francia sería, sin lugar a dudas, vista con muy buenos ojos si se pudiera aplicar a Chile.

\subsection{Diferentes modelos de financiamiento para las películas pueden ser exitosos}

Ruth Towse (2010) destaca los diferentes modelos de financiamiento que han sido razonablemente exitosos en Europa (en el capítulo 16 de su libro). Las características claves de estos enfoques en Francia, Dinamarca y Holanda se enuncian a continuación, tomando en referencia este estudio.

\subsubsection{Francia: el Estado facilita el financiamiento del sector privado.} No hay apoyo presupuestario directo

i) El apoyo presupuestario directo es brindado desde larga data a través del Centre National de la Cinématographie (CNC), que financia una amplia gama de producciones de cine y televisión con fondos provenientes principalmente de las entradas de los cines y la distribución de videos y DVDs. Aproximadamente el 30 por ciento del presupuesto es gastado en películas, en contraste con la programación televisiva.

ii) Francia también tiene incentivos tributarios para promover la inversión privada en las producciones aprobadas por el CNC y esquemas de crédito tributario que les permiten condonar 20 por ciento de sus costos de producción si son realizadas en Francia. Estos créditos tributarios también están muy difundidos en los Estados Unidos y han sido muy exitosos en algunos estados. Pero pueden ser costosos y menos efectivos en la medida en que otros estados intentan replicar esa estrategia, lo que produce un efecto neto poco claro respecto de la localización de la producción cinematográfica pero a un elevado costo para la base tributaria.

iii) Similar a otros esquemas financieros de creciente uso en el sector cultural, Francia también entrega garantías financieras a través de un instituto que es un órgano financiero puramente estatal y que alienta 
a la banca privada a compartir en partes iguales los riesgos sobre los préstamos relacionados con la producción cinematográfica, básicamente ofreciendo garantías para préstamos a productores que ya están en el negocio de la distribución.

iv) En suma, el financiamiento en Francia está organizado a través de organismos estatales, pero recurre ampliamente a los mercados privados para obtener fondos y garantías financieras. Aunque pueda sorprender para un país como Francia, no existe un sistema de subsidio público directo de moneda dura respaldada en el presupuesto de la nación.

4.3.2. Dinamarca: por lo general, el financiamiento es estatal, a través de gasto presupuestario directo

i) En 2005 la industria cinematográfica de Dinamarca estaba financiada casi en su totalidad con fondos públicos del Ministerio de Cultura, canalizados a través del Instituto Cinematográfico danés, con algunos fondos regionales adicionales.

ii) La cooperación regional es una característica original de su sistema, con financiamiento del Fondo Nórdico para el Cine y la Televisión (sustentado por cinco países nórdicos: Dinamarca, Finlandia, Islandia, Noruega y Suecia).

iii) Los dos principales radiodifusores daneses están obligados contribuir a la producción de películas a través del Instituto Cinematográfico danés (y también financian otros proyectos cinematográficos).

iv) Hasta el año 2005, Dinamarca no contaba con un esquema impositivo específico.

\subsubsection{Países Bajos: un modelo más mixto}

i) Es usual contar con esquemas de subsidios directos y de incentivos tributarios (el llamado CV para incentivar el financiamiento privado de las películas).

ii) En 2005, el Ministerio de Cultura de los Países Bajos contaba con un presupuesto de 14,8 millones de euros. Los subsidios a la producción cinematográfica eran administrados a través de una agencia subordinada, el Fondo para el Cine. Este fondo también recibía aportes de medios de radiodifusión. 
iii) En 2005, se estrenaron 31 largometrajes neerlandeses; 20 contaban con el apoyo del Fondo para el Cine.

iv) Algunos fondos provenían de mercados privados debido a regulaciones tributarias especiales establecidas por el CV para ampliar el financiamiento de la industria cinematográfica.

v) Por último, aproximadamente la mitad de los costos totales de producción de nuevas películas fueron absorbidos a través de subsidios directos e indirectos. Desde 2007, los productores que cuenten con el 65 por ciento del financiamiento de su producción pueden solicitar el 35 por ciento restante de su presupuesto. Pero el 25 por ciento del financiamiento total de la producción cinematográfica debe provenir de inversionistas privados (Towse 2010, 447).

En suma, a diferencia del financiamiento de la producción cinematográfica tipo Hollywood, libremercadista y dominada por el sector privado (pero con crecientes créditos fiscales estatales con el objetivo de llevar la producción a regiones específicas), estos esquemas europeos (similares a los de Canadá, Australia y otros países) esencialmente requieren pagos del sector privado que luego son canalizados a través del Estado a los productores cinematográficos. Sectores de la economía que cubren parte de la distribución de películas - la televisión, los medios de comunicación y las salas de exhibición_-, en la práctica, pagan esos subsidios a la producción de películas. Otra diferencia clave es que la industria cinematográfica norteamericana opera con criterios de rentabilidad. En cambio, los esquemas de subsidio europeos buscan promover la diversidad cultural y ciertos objetivos nacionales, y esto es cierto para muchos otros países, como Chile.

\subsection{Como cabría esperar, los criterios para otorgar subvenciones a los productores cinematográficos son relevantes}

Un estudio sobre las películas alemanas es un buen ejemplo respecto de este punto. Jansen (2005) halló que sólo podían identificarse unos pocos elementos determinantes del éxito de los largometrajes alemanes (por ejemplo, críticas positivas y un balance histórico de éxitos, lo que es en sí mismo interesante, porque se suele creer que el factor "nadie sabe qué va pasar", que genera caos adicional a la industria cinematográfica, haría que el éxito pasado no fuera un indicador confiable del éxito futuro). Pero en lo que concierne a la política de subsidio, su 
hallazgo notable fue que el "modelo de comité" (con opiniones expertas y un conjunto de criterios de evaluación) para determinar qué películas apoyar en la etapa del capital inicial "debilita la relación entre gastos e ingresos y distorsiona los incentivos de los productores para realizar películas adaptadas a las preferencias del público" (201).

En cambio, un modelo de subsidio de referencia tiende a brindar apoyo a productores que logran de manera consistente un "éxito" promedio superior con sus películas. Si el criterio de éxito es, por sobre todo, el resultado financiero, esto llevará a apoyar producciones cinematográficas que atraen a un público más numeroso, a pesar de que el gusto del público puede no ser consistente con estándares de valor artístico.

Jansen (2005) ofrece una salvedad a su inclinación general por los subsidios de referencia al señalar que incluso cuando las productoras vinculadas al modelo de referencia están obteniendo buenos resultados, las utilidades de la industria cinematográfica en su conjunto suelen ser negativas y "la no viabilidad económica de la industria no brinda un argumento sensato para ese tipo de subsidio" (201). Este tipo de investigación pone en evidencia algunos de los efectos contradictorios de dejar en manos de los expertos la toma de decisiones relativas a los subsidios, y las ventajas y desventajas que pueden existir al optar entre criterios "elitistas" para fomentar la calidad en el sector cultural o, por otra parte, guiarse por las señales del mercado de consumo, que son más "democratizadoras".

\subsection{Cuando un país desea desarrollar o expandir su industria cinematográfica es una estrategia mancomunada: el caso de China}

La inmensidad de China y los cambios radicales acontecidos en ese país en los últimos treinta años hacen que sea un interesante caso de estudio sobre las ventajas relativas de intentar implementar cambios acelerados. Guiying et al. (2014) identificaron cinco iniciativas del tipo de política pública que podrían introducirse en otros países que estén considerando darle un fuerte impulso inicial a la producción cinematográfica, aun cuando el contexto nacional es importante. Muchos países considerarían que este tipo de iniciativas son políticamente insustentables. Y puesto que Guiying et al. también señalan que las políticas proteccionistas de la industria cinematográfica coreana son un buen ejemplo para China, resulta aún más complicado determinar hasta qué grado 
podría adaptarse con facilidad esta estrategia completa en otros países. Las cinco iniciativas claves de China son las siguientes:

i) Subsidios de 100 millones de dólares para apoyar películas boutique a través del Ministerio Central de Finanzas.

ii) Apoyo para la aplicación de altas tecnologías en la producción cinematográfica y en el desarrollo de centros de alta tecnología (un plan con cinco subelementos específicos).

iii) Políticas fiscales específicas en apoyo a la industria cinematográfica, como el "incentivo" al sector bancario y financiero "para desarrollar nuevos productos de préstamo para la industria cinematográfica”, con algún tipo de apoyo gubernamental a los sectores bancario y financiero que entregan ese tipo de ayuda.

iv) Políticas tributarias preferenciales a la industria cinematográfica, como la exención de IVA sobre el ingreso obtenido de las copias de películas (incluidas las copias digitales), la transferencia de derechos de autor, la distribución de películas a las zonas rurales y algunas simplificaciones tributarias para los contribuyentes que provean "servicios de proyección cinematográfica".

v) Un plan ambicioso para modificar las políticas de uso de suelo a fin de promover la construcción de nuevas instalaciones cinematográficas en el país.

\section{ALGUNAS APLICACIONES ADICIONALES AL SECTOR DE LOS MUSEOS}

Chile se siente, con justa razón, orgulloso de sus múltiples museos y ha adoptado una política que ha sido muy estudiada y debatida por economistas y administradores de museos. Con fecha 3 de marzo de 2015, la Dibam (Dirección de Bibliotecas, Archivos y Museos) suprimió el cobro por concepto de ingreso a sus veintiséis museos repartidos entre el extremo norte, en Antofagasta, y el extremo sur, en Magallanes. Fue una medida audaz con la intención explícita de "volver más accesibles los museos y promover un mayor aprecio por el patrimonio de Chile" (del sitio web del Gobierno de Chile). Esta medida se asemeja a la adoptada por al menos veinte museos estadounidenses consagrados a las artes, la moda y temas específicos (una cantidad mucho mayor de museos optó por la alternativa de acceso gratuito sólo en determinados 
días hábiles y feriados). Más importante aún, se equipara con la de algunos grandes países que la han adoptado como parte de su política cultural. Aun cuando no todos los museos del Reino Unido son gratuitos, algunos de los mejores, como el British Museum y el National History Museum, sí practican esta política. Experimentos previos de admisiones gratuitas que luego fueron revertidos a una política de precios positivos significaron efectos muy negativos en las cifras de público, con bajas de casi un 20 por ciento después de la supresión de la gratuidad (AFP de Estocolmo, 10 de enero de 2008).

Suecia no fue el único país en replantearse su política de libre acceso. Como se indica en el sitio web de la Galería Uffizi en Florencia, entre algunos grandes cambios establecidos en la política de museos en Italia en 2014 figuran restricciones respecto al acceso gratuito a los museos. El principal cambio fue que las entradas gratuitas sólo están disponibles para los menores de 18 años (y un par de grupos restantes, como los docentes) y que sólo los menores de 25 años pueden optar a las entradas con descuento. Todos los demás pagan la tarifa completa; sin embargo, esta política está sujeta a eventuales cambios en el futuro. El segundo cambio fundamental es que cada primer domingo del mes los museos estatales son gratuitos como parte de la iniciativa "Domingo en el Museo". Un tercer cambio anunciado como parte del decreto ministerial es que habrá dos "Noches en el Museo" cada año calendario en las que el ingreso sólo costará un euro y el horario de visita se extenderá hasta tarde en la noche, mientras que todos los grandes museos, incluida la Galería Uffizi, tendrán un horario ampliado hasta las diez de la noche todos los viernes.

Otra estrategia de precios utilizada en varias ciudades y países son los "pases de museo", como la Tarjeta de Museo, de Holanda, con un costo de 60 euros, que permite el acceso gratuito a más de 400 museos holandeses (entre ellos, los más importantes de Amsterdam) por un período de 12 meses. Esta forma de tarificación, sin embargo, plantea interrogantes respecto de cómo repartir los ingresos entre los museos participantes.

Los economistas y otros investigadores de la cultura han llegado a importantes conclusiones en lo relativo al crítico tema de los precios de admisión a los museos y otras opciones de política. Tres de estas conclusiones son analizadas a continuación. 
i) A pesar de que el ingreso sin costo a los museos es una causa muy loable, no es aplicable de forma universal, y en algunos casos puede justificarse, por razones económicas (y no sólo financieras), la existencia de precios positivos.

Desde una mera perspectiva financiera, el cobro de precios positivos genera ingresos (más aún si la elasticidad de precios de la demanda para visitas a los museos es baja, como suele suceder cuando el rango de precios es nulo o modesto). Esto es especialmente relevante cuando el objetivo de los museos es no sólo atraer visitantes, sino también mantener una mayor solvencia fiscal para sustentar sus múltiples programas. Sin embargo, no está claro que precios positivos o, en términos más generales, precios más altos de admisión generen mayores ingresos al museo. Incluso ignorando los temas relacionados con la magnitud de la elasticidad de precios de la demanda (y otros temas relacionados, detallados a continuación), los economistas están conscientes de la literatura sobre "exclusión" (crowding out), que ha puesto en evidencia que en algunos casos un incremento en los ingresos de los museos (y otras organizaciones) más tarde se traduce en una reducción del apoyo estatal por la vía de los impuestos generales, lo que lleva a pensar que no hay razón a priori para afirmar con certeza que los ingresos totales de los museos se incrementarán como resultado de un esfuerzo por generar un mayor ingreso vía ganancias. Para complicar aún más el tema de los efectos completos sobre el ingreso total, es probable que los administradores de los museos hayan comprobado que la entrada gratuita puede, en la práctica, generar mayores ingresos si los visitantes compran alimentos en la cafetería o mercancías y souvenirs en las tiendas. Al igual que con las salas que exhiben películas, estos ingresos adicionales pueden superar con creces los ingresos por concepto de entradas.

Ahora bien, la generación de ingresos lucrativos laterales presupone que los museos dispongan de instalaciones atractivas para los visitantes y sean capaces de generar esos ingresos. Como parte de la nueva política de museos implementada en Italia en 2014, el gobierno diseñó una reforma profunda para arreglar el inoperante sistema de museos. Ésta contemplaba una mayor privatización y la introducción de servicios adicionales. Para muchos observadores, el manejo estatal se había vuelto desastroso y el desempeño de los museos italianos era claramente deficiente en términos de su capacidad para generar ingresos. Un 
artículo en el The Guardian (21 de diciembre de 2014) describió cómo Italia estaba introduciendo un enfoque más privado en la gestión de sus museos y citó la impactante comparación respecto a que el restaurante del Metropolitan Museum de Nueva York por sí solo generaba más ingresos que todos los museos italianos reunidos. En cuanto a Francia, se señalaba que el Louvre había generado 2,5 mil millones de euros en ventas totales en 2013.

Según el The Guardian (2014), sólo 190 de los 450 museos estatales italianos ofrecían instalaciones y servicios adicionales a los turistas. Por ello, llamaron a licitaciones privadas e invitaron a empresas internacionales para remodelar sus museos. Pero algunos se opusieron a la medida, como el director de un museo en Modena que renunció después de que su institución abrió las puertas a una feria gastronómica con productos locales. Sus palabras fueron: "Expulsar el arte y remplazarlo con productos típicos crea la imagen de una ciudad que atiende al turismo de consumo en lugar de hacerlo a ciudadanos reflexivos" (The Guardian, 21 de diciembre de 2014).

También existen razones de mera eficiencia económica para fijar precios bajos o nulos en los museos, al asumir que no existe una demanda multitudinaria (al menos no para todas las exposiciones o para todos los horarios de visita). En la medida en que existe una considerable "capacidad excesiva para visitantes al museo", el costo para la sociedad de un visitante adicional al museo o a la galería es literalmente nulo. Por ende, existe un argumento económico para afirmar que no hay justificación para disuadir a cualquier visitante potencial que incluso tenga un valor marginal muy bajo, puesto que, con el costo social marginal de cero dólares, cualquier valor positivo de consumo de esa visita adicional vendría a sumarse al valor económico neto total.

Ahora bien, para muchos museos y en las horas álgidas de visitas no existe ese espacio excedente $y$, al igual que con muchos otros ejemplos en economía de "precios de demanda peak", resultaría eficiente cobrar precios positivos para disuadir a los visitantes de acudir al museo en las horas de punta (que reducen de manera notable el valor educativo y de consumo de la experiencia). Como lo señalan Prieto-Rodríguez y Fernández-Blanco (2011), a pesar de que uno puede justificar algún tipo de financiamiento estatal como resultado de plausibles beneficios externos positivos de ir al museo, no puede negarse que los visitantes se benefician más que los no visitantes. Por ello, el importante "principio 
de contribución (benefit taxation) sugiere que el financiamiento público debe ser complementado con tarifas" (293).

ii) A pesar de que son populares y defendibles, los beneficios para la sociedad de utilizar "pases de museos" (y, de manera más general, pases culturales) están sujetos a la capacidad de desarrollar la regla de reparto óptimo de los ingresos para solucionar el llamado, justamente, "problema de los pases de los museos".

El análisis económico de esta regla de asignación puede ser bastante complejo. No puede establecerse la "regla ganadora" sin aclarar las metas y los objetivos de las asignaciones, y esto puede variar según los públicos y las ubicaciones de los museos, pero tomar conciencia de esta complejidad es importante desde una perspectiva política. Como lo indican Casas-Méndez et al. (2014, 195-196), las opciones de reparto más importantes son las siguientes:

a) El enfoque de "reparto proporcional a las pérdidas" (asignar los ingresos totales por concepto de pases en proporción a las pérdidas de cada museo por vender menos entradas individuales debido a su aceptación del pase.

b) La regla de "repartir de manera proporcional al número de visitas" (se asignan los ingresos por concepto de pase en proporción al número de visitantes que reciba cada museo que se hace parte del convenio).

c) El enfoque "igualitario" (como el nombre lo indica, simplemente divide los ingresos por concepto de pase de manera equitativa entre todos los museos participantes).

d) Existen otros enfoques más dudosos como el "de valor proporcionado" y el de "quiebra".

iii) Hay temas relevantes relacionados con las regulaciones y los derechos sobre la propiedad que afectan a los museos y que pueden incidir mayormente en su capacidad para lograr la combinación óptima de investigación, conservación, difusión al consumidor y otros servicios para el público.

El economista Bruno Frey ha sido un gran defensor de determinadas políticas museísticas y uno de sus libros sobre política cultural (2000) generó un análisis de por sí revelador, que destaca muchas de esas políticas (Toepler 2002). Frey quisiera que Europa adopte más políticas de tipo estadounidense: sacar obras de circulación, otorgar- 
les a los directores de museo la libertad para vender obras de arte de sus colecciones, a fin de optimizar el funcionamiento de los museos, incluidas sus adquisiciones y operaciones. Pero incluso en los Estados Unidos cualquier apoyo para el retiro de obras de circulación se centra en estrategias óptimas de colección y adquisición y en los mejores enfoques para compartir activos culturales entre museos y regiones. No es una práctica usual en los museos estadounidenses recurrir a la venta de partes de una colección con el único objeto de cubrir pérdidas financieras. Existen efectivamente motivos que justifican una mayor flexibilidad en la gestión de los museos, ya que nadie podrá contemplar ni siquiera una parte de una colección si las puertas del museo se cerraran por problemas financieros. Pero aún existe una clara resistencia a dar este paso, pese a la eventualidad de que la venta de una obra de arte a otro museo posibilite que ésta pueda seguir siendo contemplada por el público, más aún si formaba parte de la "colección de bodega". En cambio, la venta de obras a coleccionistas privados, aunque sea por necesidades perentorias de fondos para seguir operando, las alejaría del alcance del público.

Frey también critica las regulaciones y restricciones usualmente impuestas en Europa por los gobiernos o los sindicatos a las instituciones culturales, obligando a estas últimas a transferir todos sus ingresos netos al Estado al final del año fiscal. Esto genera un desincentivo para aumentar los ingresos. También merma la voluntad de organizar exposiciones grandes y lucrativas, ya que cualquier ganancia adicional irá a parar a las arcas fiscales y no beneficiará directamente a los museos. Un ejemplo de ello, en Alemania, es el caso de un director de museo que logró negociar con éxito un acuerdo de reparto de utilidades con el gobierno, pero resultó complejo y demoroso, con altos costos transaccionales, y posiblemente este esquema no sería sustentable si estas exposiciones especiales se volvieran periódicas y tuvieran que ser negociadas en cada ocasión (Toepler 2002). Toepler también señala que la Galería Nacional de Berlín tiene muchas exposiciones organizadas por los Amigos del Museo y otros patrocinadores privados que, en tanto entidades no públicas, están legalmente autorizadas a quedarse con las utilidades. Esto también supone costos transaccionales para negociar con los auspiciadores sin fines de lucro, pero modifica la estructura de incentivos y puede aumentar la oferta de exposiciones especiales. 


\section{ALGUNAS APLICACIONES ADICIONALES AL PATRIMONIO CULTURAL Y LA RESTAURACIÓN URBANA}

La preservación del patrimonio cultural puede referirse a "antigüedades", tales como objetos, íconos religiosos, obras de arte, edificios y monumentos del pasado histórico. Pero también apunta a la conservación de activos "marítimos" (barcos hundidos y sus contenidos) o, incluso, centros productivos posteriormente revalorizados como emplazamientos industriales históricos y que constituyen vitrinas de la vida cotidiana de civilizaciones antiguas y modernas.

Un caso especialmente cautivante es la preservación de "sitios patrimoniales urbanos", que generalmente corresponden a centros históricos urbanos que se encuentran en un estado de relativo abandono producto de la modernización de las economías, el crecimiento demográfico y el consiguiente desvío de recursos hacia otras zonas de las grandes áreas metropolitanas. Son muchos los ejemplos que se puede citar, con diferentes grados de éxito en la restauración: Santo Domingo (República Dominicana), La Habana (Cuba), Cartagena de Indias (Colombia), Antigua (Guatemala), Brujas (Bélgica), Quito (Ecuador), Oaxaca (México), Nueva Orleans (Estados Unidos), Colonia de Sacramento (Uruguay) y Salvador de Bahía (Brasil). Existen variaciones urbanas modernas respecto al tema de la preservación, centradas en el desarrollo del uso de suelo y los beneficios en términos de calidad de vida de mantener y ampliar espacios públicos, espacios peatonales amigables y la vitalidad de barrio que no tienen un especial sello histórico, pero que sirven de hogar para millones de personas y como entornos transformadores en la vida de los jóvenes.

Al igual que con los cines y los museos, Chile ha jugado un destacado papel en el debate sobre una política cultural óptima y se suele citar como ejemplo el centro histórico de Valparaíso (Rojas 2013). Un espacio urbano muy distinto a la ciudad de Valparaíso, en cuanto a su atmósfera, es la comuna de Providencia, ubicada en la ciudad de Santiago, donde el Paseo Las Palmas y el pasaje entre Santa Magdalena y Nueva Lyon, por ejemplo, han sido citados como un modelo de asociación público-privada para establecer espacios públicos funcionales y entornos peatonales amigables (Mora y Zapata 2004; Schlack 2007; Bannen 1993). 
Las políticas en este ámbito incluyen muchas opciones legales y normativas, tales como regulaciones territoriales en relación con el uso de suelo. La política tributaria ha sido también importante $\mathrm{y}$, al igual que en la política general sobre patrimonio, la tradicional hegemonía del sector público ha ido cambiando de manera notable e incorporando de manera creciente al sector privado. Esto representa una oportunidad y un desafío para una política pública exitosa.

Se pueden extraer algunas importantes lecciones de principios económicos básicos, así como de la experiencia de otros países e investigadores en esta área. Algunas de ellas son:

i) La primera lección no se aplica de manera exclusiva a la preservación del patrimonio cultural, pero adquiere especial fuerza en las políticas dirigidas a este ámbito: existe una valoración marginal decreciente respecto de la preservación, lo que hace que los beneficios adicionales esperados por preservar un jarrón adicional del siglo II antes de Cristo sean inferiores a los de iniciar el proceso de restauración del primer edificio en ruinas en el centro histórico de La Habana. Aun cuando esto apunta a un tipo de "optimización internacional", el punto se aplica a cualquier país que esté tratando de determinar la mejor estrategia para proteger su patrimonio histórico.

De hecho, la "norma de decisión" correcta consistiría en asignar recursos de preservación limitados, para que el beneficio marginal por dólar de gastar en X sea lo más cercano posible al beneficio marginal por dólar gastado en Y y Z. Dada la complejidad de valorizar activos patrimoniales (y las limitaciones de basarse en las reglas del libre mercado o de recurrir al dictamen de un experto público respecto del "valor inherente"), establecer esa regla apunta principalmente a recordarle a los diseñadores de políticas las ventajas y desventajas asociadas, más que brindarles una regla matemática que puedan aplicar.

La más visible evidencia de la necesidad de atender este desafío de política es la controversia permanente sobre la identidad de los sitios "Patrimonio de la Humanidad", de la Unesco, que han sido criticados en muchas oportunidades por economistas y otros, en parte porque casi la mitad están situados en los países más ricos de Norteamérica y Europa. Puede debatirse si esto refleja sesgos de influencia política regional, un fracaso implícito en desarrollar un conjunto más amplio de criterios con otras "ponderaciones culturales" o simplemente son las realidades 
de los países modernos lo que les ha permitido a ellos mismos ser capaces (muchas veces a través de iniciativas internacionales) de preservar sitios patrimoniales (contando de este modo con más "candidatos" para su posible inclusión en la mentada categoría).

A nivel nacional, algo que puede ser útil para los diseñadores de políticas en Chile, debe hacerse notar que para muchos países el foco principal de su política de patrimonio nacional consiste en completar o definir mejor las "reglas de clasificación" respecto al conjunto de activos culturales que deben ser preservados. Algunos investigadores han identificado esto como el foco de Austria, Azerbaiyán, Chipre, Irlanda y Portugal (Klamer et al. 2013). También resultan de interés otras cinco actividades relacionadas con la política de preservación del patrimonio nacional identificadas por estos autores (42):

a) Reorganizar las instituciones responsables de la conservación del patrimonio y mejorar la legislación relacionada con dicha preservación (por ejemplo, el Reino Unido y Holanda).

b) Promover el turismo cultural (por ejemplo, Bulgaria, Grecia, Italia y Rusia). Este es también un objetivo de Chile, tal como ha sido declarado por su Consejo Nacional para la Cultura y las Artes (CNCA 2011), y que considera promover "el patrimonio cultural material e inmaterial como fin turístico; vinculante con el desarrollo socio-económico regional".

c) Estudiar el impacto económico y la "sustentabilidad de cualquier intervención a favor del patrimonio cultural". Klamer et al. (2013) citan los casos de Alemania y Francia como ejemplares, al haberse también enfocado en los impactos sobre el empleo durante las fases de los proyectos para preservar y restaurar monumentos históricos y sitios patrimoniales (especialmente, pero no sólo exclusivamente, en el contexto de la recesión mundial de 2008 que afectó a tantos países).

d) Explorar formas óptimas de involucrar al sector privado, como el desarrollo de incentivos fiscales más creativos.

e) Ampliar el alcance de la protección del patrimonio más allá de los activos patrimoniales tangibles, es decir, hacia idiomas, tradiciones culturales y danzas nativas, entre otros. EL CNCA de Chile plantea como uno de sus objetivos "salvaguardar las expresiones y las manifestaciones de las comunidades indígenas e inmigrantes". 
Klamer et al. (2013) señalan que este foco ha sido evidente desde hace muchos años en países como Japón, pero que la preocupación por la preservación del patrimonio intangible en la mayoría de los países occidentales es relativamente nueva, excepto en algunas zonas de Europa donde la preservación de la identidad cultural ha sido especialmente problemática (por ejemplo, las regiones valonas y flamencas de Bélgica o Sicilia dentro de Italia, y también podrían citarse los diversos conflictos regionales dentro de España, como el País Vasco y Cataluña).

ii) Existen diversos modelos para limitar la "excesiva influencia de los políticos y los burócratas" en decisiones de inversión sobre el patrimonio cultural, más allá de las permanentes oscilaciones a favor de privatizar la preservación del patrimonio cultural. Éstos apuntan esencialmente a involucrar de mejor manera a otros actores claves, como la población general y grupos privados con intereses adquiridos.

Klamer et al. (2013) vuelven a enunciar varios de estos modelos, aunque destacan la variedad de opciones utilizadas (39-40):

a) El llamado "sistema británico", a través del cual las agencias estatales de las regiones de Inglaterra, Gales, Escocia e Irlanda del Norte asignan fondos para el patrimonio cultural a órganos públicos no departamentales (NDPB, por su sigla en inglés), que tienen la responsabilidad de distribuir esos fondos directos gubernamentales a determinados proyectos y postulantes a fondos. A pesar de que estos órganos públicos deben rendir cuentas a las reparticiones regionales, son independientes y no están sujetos a un control político manifiesto. También citan los casos de Holanda, Suecia y Noruega por promover esas organizaciones independientes.

b) En algunos casos, se les confiere a esos órganos "independientes y semiautónomos" un rol asesor del Ministerio de Cultura. Las decisiones finales siguen recayendo en el ministerio, pero esto abre la posibilidad de que el gobierno no tenga que emitir juicios de valor en temas claves - lo que suele suscitar suspicacias - y que se apoye extensamente en los juicios de estos grupos asesores. Estos últimos, cuando trabajan de manera efectiva, procuran reflejar una gama mucho más amplia de intereses que un comité de expertos, al cual se le suele reprochar que promueve sólo una cultura refinada para élites. 
c) La descentralización es una estrategia para evitar de manera más explícita los abusos resultantes de la excesiva centralización en la toma de decisiones. Klamer et al. (2013) citan a Alemania, Austria y España como buenos ejemplos de ese enfoque.

iii) Parte importante de la política de restauración urbana y patrimonial suele basarse en teorías sobre el desplazamiento de las personas, ya sea turistas que realizan visitas temporales (preocupación central para quienes privilegian el turismo patrimonial) o profesionales más talentosos y dinámicos (por lo general, más jóvenes), que pueden ser inducidos a trasladarse por períodos más largos a "ciudades culturalmente creativas", más atractivas, $\mathrm{y}$, por esa misma vía, atraer a nuevas empresas que verán en la disponibilidad de esa fuerza de trabajo local más talentosa un factor clave para sus propias decisiones de localización. Sin embargo, por muy importantes que hayan sido las esperanzas de relocalización para los diseñadores de políticas, la evidencia empírica sigue siendo muy incierta.

En lo que respecta al turismo cultural, no hay mejor síntesis respecto del dilema que enfrentan los diseñadores de políticas que el que brinda Lluis Bonet, economista cultural radicado en Barcelona (ciudad considerada desde hace mucho tiempo como una gran beneficiaria del turismo cultural). Esta es una cita directa suya, en la que se refiere a estudios de la Organización Mundial de Turismo para fundamentar sus opiniones:

La paradoja es que, pese a la consolidación de un mercado turístico cultural específico y creciente, la mayoría de los turistas que consumen productos culturales no escoge su destino principalmente por ese motivo. Las atracciones patrimoniales, componente central de la demanda turística, son, en la mayoría de los casos, uno de los múltiples factores que explican las motivaciones del viajero. Las personas que visitan a familiares, que asisten a conferencias o ferias comerciales, que realizan un descanso de fin de semana o incluso que disfrutan de sus vacaciones estivales, combinan el ocio o los negocios con el consumo de servicios culturales junto con otras actividades. Por lo tanto, el turismo incluye tanto a los turistas muy motivados como a un grupo más amplio de consumidores culturales que viajan con motivaciones variadas. (Bonet 2013, 19) 
Bonet cita varias encuestas realizadas por la European Association for Tourism and Leisure Education (Atlas), en las que se señala que sólo entre el 20 y 30 por ciento de los visitantes entrevistados en los sitios patrimoniales y los espectáculos culturales indicaron esas atracciones como la razón para escoger esa región como su lugar de destino.

De hecho, es sabido que entre los muchos motivos que llevan a sobreestimar el impacto económico de un determinado objeto está el que en los estudios ex ante figura la falsa atribución a ese objeto de todos los gastos directos y adicionales que realizan los visitantes a una región (Seaman 2011). En efecto, los estudios sobre el impacto económico de grandes exposiciones de arte o destacados eventos deportivos han tenido que reducir los impactos regionales para dar debida cuenta de este "ajuste motivacional".

En cuanto a la literatura sobre "ciudades creativas" que ha proliferado principalmente a partir del trabajo del investigador urbano Richard Florida (2002), la evidencia empírica de esta teoría — que postula que "si uno crea una ciudad creativa las personas talentosas acudirán y, con ellas, el éxito económico" - ha sido muy dispar y criticada. Hay muchas cosas atractivas en la teoría de Florida, y los economistas de la cultura (y muchos promotores del sector cultural) celebraron la noción de que se pudiera asegurar un crecimiento rápido y éxito en el largo plazo mostrando tolerancia a la diversidad e invirtiendo en activos culturales que le den una alta valoración a una ciudad en el índice de ciudades creativas de Florida (un índice, por cierto, muy codiciado en sus primeros puestos).

Pero pese a existir alguna evidencia que respalde esta idea, los críticos hallaron muchos puntos dudosos, entre ellos que varios de los factores que Florida identificaba como atractivos para las personas jóvenes, dinámicas y talentosas no se correspondían en absoluto con los factores concebidos por quienes defienden la expansión del sector cultural. Más bien, se relacionaban con una intensa vida nocturna, abundantes bares y cafés y atractivos escenarios para encuentros entre solteros. Pese a ello, muchas personas del mundo de las artes consideraban que las mayores inversiones en museos, teatros y salas de espectáculos escénicos que propugnaba Florida se justificaban ampliamente. Sin embargo, había considerable evidencia de que la verdadera atracción la constituían las cafeterías originales y los clubes para solteros Más aún, la definición de "empleo creativo" de Florida era simplemente "altos in- 
gresos", sin una clara distinción entre los trabajos creativos vinculados a las artes (los cuales, por lo demás, suelen no ser bien remunerados) y los empleos bien pagados pero, por lo general, no creativos, vinculados a contadores, abogados y corredores de bolsa. Y la evidencia empírica que relacionaba las diferentes versiones del índice de creatividad de Florida con el crecimiento del empleo en las ciudades o con un crecimiento económico por sobre el promedio no era muy sólida, cuando no simplemente ausente.

Sin embargo, existe evidencia de que los barrios con más paseos peatonales, espacios públicos, parques, ciclovías y tránsito público atraen a los jóvenes dinámicos. Y barrios céntricos y periféricos en los Estados Unidos (incluso en ciudades con grandes suburbios, como Atlanta y Georgia) han experimentado notables crecimientos demográficos en parte debido al uso de importantes herramientas, como los distritos tributarios especiales descritos en la sección 2, en que las empresas de una comuna aceptan que se les apliquen impuestos adicionales para que los fondos sean asignados a la mejora de las calles, mayor seguridad, ampliación de los parques, entre otros. Esto sugiere potenciales ganancias para el tipo de mejoras que se han introducido, por ejemplo, en el barrio de Providencia. Estas mejoras en la calidad de vida son valiosas, incluso si no atraen nuevas personas pero mejoran las vidas de los actuales residentes.

Por ello, pese a la dispar y a veces inconsistente evidencia a favor de una "relocalización" en materia de políticas patrimoniales, existen elementos que respaldan el desarrollo de políticas de uso de suelo que incentiven más espacios urbanos y asociaciones público-privadas para mejorar la vida de los peatones en nuestras ciudades. A pesar de que los partidarios del sector privado suelen ver el uso de restricciones zonales como obstáculos que deben ser tolerados, o incluso burlados, un enfoque más exitoso consistiría en combinar los necesarios incentivos zonales con esfuerzos en pos de reducir y compartir el riesgo con inversionistas privados.

\section{OBSERVACIONES FINALES}

Chile ha contribuido y es el potencial beneficiario de un amplio inventario de experiencias acumuladas a lo largo de diversos países en 
materia de aplicación de distintos enfoques sobre política cultural. A pesar de que puede resultar complejo y tedioso documentar y tratar de entender los detalles de muchas de esas iniciativas de política, las cinco grandes lecciones enunciadas en la sección 2, incluida la necesidad de ser suficientemente creativo para reconocer que la política cultural no es sólo una política de subsidios y tiene al menos cinco dimensiones adicionales, siguen constituyendo el marco general para una evaluación de la amplia diversidad de iniciativas públicas de que disponen los diseñadores de políticas culturales.

\section{REFERENCIAS}

Abbing, Hans. 2002. Why are Artists Poor? The Exceptional Economy of the Arts. Amsterdam: Amsterdam University Press.

Bannen, Germán. 1993. "El comercio en Providencia". Revista CA 72.

Banternghansa, Chanont \& Kathryn Graddy. 2011. "The Impact of the Droit de Suite in the UK: An Empirical Analysis". Journal of Cultural Economics 35: $81-100$.

Barnes, Hilary. 2013. "Protectionism and Films". Op Ed. Syndication, 23 de junio.

Bonet, Lluis. 2013. "Heritage Tourism". En Handbook on the Economics of Cultural Heritage, editado por Ilde Rizzo \& Anna Mignosa. Cheltenham: Edward Elgar Publishing Limited.

Breslin, Herbert. 2004. The King and I: The Uncensored Tale of Luciano Pavarotti's Rise to Fame by His Manager, Friend and Sometime Adversary. Nueva York: Doubleday.

Casas-Mendez, Balbina, Vito Fragnelli \& Ignacio García-Jurado. 2014. "A Survey of Allocation Rules for the Museum Pass Problem". Journal of Cultural Economics 38 (3): 191-205.

Chamarnaud, Luc, Victor Ginsburgh \& Philippe Michel. 2008. "Can Pubic Arts Education Replace Arts Subsidization?" Journal of Cultural Economics 32 (2): 109-126.

CNCA (Consejo Nacional de la Cultura y las Artes). 2011. Política cultural 2011-2016. http://www.cultura.gob.cl/wpcontent/uploads/2011/11/politica cultural_2011_2016.pdf

Fedeli, Silvia \& Michele Santoni. 2006. "The Government's Choice of Bureaucratic Organization: An Application to Italian State Museums". Journal of Cultural Economics 30 (1): 41-72.

Florida, Richard. 2002. The Rise of the Creative Class. Nueva York: Basic Books.

Georgiou, Christina. 2011. "What Is a Neighborhood Improvement District?". Patch-Poster, 28 de mayo. 
Guiying, Guo, Tang Ling Xiao \& Elaine Wang. 2014. "Policies Supporting Chinese Film Industry Have Been Announced". China Law Insight, 7 de julio. http:// www.chinalawinsight.com/2014/07/articles/antitrust-international-trade/ policies-supporting-chinese-film-industry-have-been-announced/.

Jansen, Christian. 2005. "The Performance of German Motion Pictures, Profits and Subsidies: Some Empirical Evidence”. Journal of Cultural Economics 29 (3): 191-212.

Klamer, Arjo, Anna Mignosa \& Lyudmila Petrova. 2013. "Cultural Heritage Policies: A Comparative Perspective". En Handbook on the Economics of Cultural Heritage, editado por Ilde Rizzo \& Anna Mignosa. Cheltenham: Edward Elgar Publishing Limited.

Mora, Rodrigo \& Isabel Zapata. 2004. "Comercio, espacio público y gestión local: el caso de Providencia en Santiago de Chile". Revista de Urbanismo 9 (marzo).

Mossetto, Gianfranco. 1992. “A Cultural Good Called Venice”. En Cultural Economics, editado por Ruth Towse \& Abdul Khakee. Berlin-Heidelberg: Springer Verlag.

Noonan, Douglas S. 2013. "Market Effects of Historic Preservation”. En Handbook on the Economics of Cultural Heritage, editado por Ilde Rizzo \& Anna Mignosa. Cheltenham: Edward Elgar Publishing Limited.

Orme, Tyler. 2014. "The Short- and Long-Term Effectiveness of Anti-Piracy Laws and Enforcement Actions". Journal of Cultural Economics 38 (4): 351-368.

Prieto-Rodríguez, Juan \& Víctor Fernández-Blanco. 2011. “Optimal Pricing and Grant Policies for Museums”. Journal of Cultural Economics 30 (3): 169-181.

Rojas, Eduardo. 2013. "The Public Sector in the Preservation of Urban Heritage Sites: Lessons from Four Cities in Latin America". En Handbook on the Economics of Cultural Heritage, editado por Ilde Rizzo \& Anna Mignosa. Cheltenham: Edward Elgar Publishing Limited.

Schlack, Elke. 2007. "Espacio público". Conferencia dada en abril de 2007.

Seaman, Bruce. 2010. "Pricing Strategies". En Handbook of Research on Nonprofit Economics and Management, editado por Bruce A. Seaman \& Dennis R. Young. Cheltenham: Edward Elgar Publishing Limited.

- 2011. "Economic Impact of the Arts". En A Handbook of Cultural Economics, Second Edition, editado por Ruth Towse. Cheltenham: Edward Elgar Publishing Limited.

- 2013. "The Role of the Private Sector in Cultural Heritage". En Handbook on the Economics of Cultural Heritage, editado por Ilde Rizzo \& Anna Mignosa. Cheltenham: Edward Elgar Publishing Limited.

Souza, Gustavo Fernandes, Ana Flávia Machado \& Edson Paulo Domingues. 2016. "Economic Impacts of the Vale-cultura (culture voucher): A Computable General Equilibrium Model". Documento de trabajo.

Sraker, Andrej, Jadranka Plut \& Mojca Marija Pungerčar. 2016. "Special Measures to Support Self-Employed in Slovenia and Their Effects". Documento de 
trabajo financiado por el Consejo Nacional para la Cultura de la República de Eslovenia.

Stockholm Agence France Presse (AFP). 2008. "No Longer Free, Swedish Museums See Big Drop in Visits". 10 de enero.

The Guardian. 2014. "Italy to Bring Private Sector into Its Museums in Effort to Make a Profit". 21 de diciembre.

Throsby, David \& Anita Zednik. 2011. "Multiple Job-Holding and Artistic Careers: Some Empirical Evidence". Journal of Cultural Trends 20 (1): 9-24.

Toepler, Stefan. 2002. "Review of Bruno S. Frey's, 2000. Arts \& Economics: Analysis \& Cultural Policy”. Journal of Cultural Economics 26 (1): 79-81.

Towse, Ruth. 2010. A Textbook of Cultural Economics. Cambridge, Reino Unido: Cambridge University Press.

Ward, Kevin. 2007. "Business Improvement Districts: Policy Origins, Mobile Policies and Urban Livability”. Geography Compass 1 (3): 657-672. EP 